\title{
Assigning Robust Default Values in Building Performance Simulation Software for Improved Decision-Making in the Initial Stages of Building Design
}

\author{
Kyosuke Hiyama ${ }^{1,2}$ \\ ${ }^{1}$ Faculty of Engineering, Yamaguchi University, 2-16-1 Tokiwadai, Ube-shi, Yamaguchi 755-8611, Japan \\ ${ }^{2}$ Massachusetts Institute of Technology, Cambridge, MA 02139, USA \\ Correspondence should be addressed to Kyosuke Hiyama; hiyama@yamaguchi-u.ac.jp
}

Received 5 June 2014; Revised 17 October 2014; Accepted 28 October 2014

Academic Editor: Pieter Pauwels

Copyright (C) 2015 Kyosuke Hiyama. This is an open access article distributed under the Creative Commons Attribution License, which permits unrestricted use, distribution, and reproduction in any medium, provided the original work is properly cited.

Applying data mining techniques on a database of BIM models could provide valuable insights in key design patterns implicitly present in these BIM models. The architectural designer would then be able to use previous data from existing building projects as default values in building performance simulation software for the early phases of building design. The author has proposed the method to minimize the magnitude of the variation in these default values in subsequent design stages. This approach maintains the accuracy of the simulation results in the initial stages of building design. In this study, a more convincing argument is presented to demonstrate the significance of the new method. The variation in the ideal default values for different building design conditions is assessed first. Next, the influence of each condition on these variations is investigated. The space depth is found to have a large impact on the ideal default value of the window to wall ratio. In addition, the presence or absence of lighting control and natural ventilation has a significant influence on the ideal default value. These effects can be used to identify the types of building conditions that should be considered to determine the ideal default values.

\section{Introduction}

Just as the implementation of high-efficiency HVAC and lighting systems and the use of natural energy are necessary in green building design, a well-designed architectural plan is important to minimize energy use in the building. Computer simulation tools, such as energy simulation tools, can be very useful in the development of such an optimal architectural plan [1]. For example, energy simulation tools can be useful in producing an enhanced sketch of the building shape that best minimizes energy consumption in early stages of the building process [2].

The implementation of energy simulation tools at the early stages of building design has high value in view of energy saving. However, energy simulation tools require several inputs. It makes energy simulation a time-consuming task [2]. In addition, the numerous uncertainties in these inputs make it difficult to perform an energy simulation efficiently in the real design process, especially when determining the building shape in the early stages of building design [3]. Information based on simulations with poor choices for the inputs may provide inaccurate information for decision making. It may also cause poor building performance.

How to handle the uncertainties is also an important topic in building information modeling (BIM [4]) technology development [5]. Based on this philosophy, the author has been developing an optimal building design aid system that integrates computer aided design (CAD), building environmental simulation tools and an optimization algorithm, based on the concept of BIM [6]. As an answer to these discussions, a new method assigning default values based on the past project records in building performance simulation software has been proposed [7]. The default values are defined as tentative values that are required in simulations 
in the initial stages of building design. The usage reduces the errors in building environment assessments by increasing the robustness of the building performance simulation results. In this paper, a more convincing argument is presented to utilize the new method to assign appropriate default values to a new building project.

\section{Definition and Importance of Default Values at Early Stages of Building Design}

The building shape has a large impact on the energy consumption of the HVAC and lighting systems. Thus the building shape is assigned first priority in the design [810]. In this context, the optimal building shape in view of energy saving should be developed as early as possible in the initial design stage $[11,12]$. The façade, including the window proportions and the window areas, might be dictated by the architectural style and the sketch ideas could be guessed at the same time when the building shape is studied. However, the suitability for the building performance is not validated at this stage. Thus, these parameters should be optimized at the next design stage [13]. In addition, façade composition including glazing type and thickness for external walls might be dedicated based on green building guidelines. However, the optimal figures for these parameters vary according to building layout including the orientation [14]. Thus, these parameters might be changed due to detailed thermal energy and economic analysis at the later design stages. In these contexts, the sketch of the building shape should be studied in conjunction with the uncertainties in the façade features.

To carry out an energy simulation at this early design stage, tentative values must be carefully chosen for the numerous inputs that have not yet been determined. Some studies have identified the lack of quality in the model data related to the uncertainty as one of the main issues preventing the effective adoption of BPS in industry. Despite the development of BIM technology, which can aid in the input of building geometry, tentative values are still necessary for building properties and all nongeometric data inputs, such as the window properties [15]. In this study, these tentative values with uncertainty are called "default values" [7]. The use of "default values" is an advantage in many simulation tools; however, input quality control is one of the missing features regarding usability [16]. For example, the building proportion is a design variable when the building shape sketch is being developed. Meanwhile, the other values such as the window properties and the wall compositions that are studied at a later stage must be treated as "default values." However, the design variables should include not only the building shape but also those default values that affect the optimization outputs. That is, the optimal design value is highly affected by the default values. A poor choice of default values, therefore, can direct an architect toward ineffective building shapes, which can result in buildings with high energy consumption. In other words, a realistic design approach is to introduce ranges of uncertainty in the simulation parameters including the default values [17]. In particular, the window properties, such as the glazing percentage and the orientation, strongly influence the output
[18]. Moreover, the building operation, for example, the implementation of natural ventilation, affects the optimal window properties [19]. Thus, thoughtful consideration is required in assigning default values to the window properties. The optimized design solutions must be robust enough to changes in the design conditions and to identify solutions that are less susceptible to uncertainty [20]. Thus, the demand of research for investigating the sensitivity of design condition is increasing [21].

To ensure the robustness of the optimized design solution, background data, such as the energy simulation results, should also be sufficiently robust to the uncertainties in the inputs, which may vary in subsequent design stages. Thus, the ideal default value should be defined to ensure robustness. The default values should comprise the values that maximize the robustness instead of the optimal values that minimize the object functions, such as energy consumption. Note that the default values are expected to be treated as design variables and will be optimized in a subsequent design stage.

It is difficult to find a global default value that can be applied to any type of building design. The optimal building design is strongly dependent on the climate [21]. Thus, building components that can be adapted to different climates should be employed.

The question then arises as to whether default values based on different climates can be developed, just as each country has its own green building guidelines. It may be possible to define appropriate default values for simple properties such as the glazing type. However, window properties such as the window geometry are strongly dependent on the building shape and the building operation [18]. That is, the original window properties of each building should maximize the energy efficiency based on the building shape and operation. Therefore, there are as many appropriate default values as there are varieties of buildings [7].

To assign appropriate default values to a new building project, an experienced architect searches for the best practice that shows similarities to the new project to minimize ranges of uncertainty. In a survey of current building simulation workflows in professional practice, $31 \%$ of the participants indicated that they reused a previous model for building information inputs [15]. An architect usually aims to determine the best practice that is suitable for a new project. BIM can help to reduce the effort expended by architects in searching for best practices.

In BIM technology development, data-mining techniques are controversial [22]. However, there appears to be less debate on how to search for data from existing building data sets. The building information is represented as the assembly of objects in BIM that employs the object-oriented databases. Existing building objects are highly developed adaptations to previous building projects that account for the unique features of the building. These concepts can be used in knowledge transfer methods by employing the features of existing building parts to benefit a new building design that has similarities to the previous project [23]. In a previous paper, a method was presented for using building attributes for a new project that had been optimized using previous building designs [7, 24]. Figure 1 shows the 


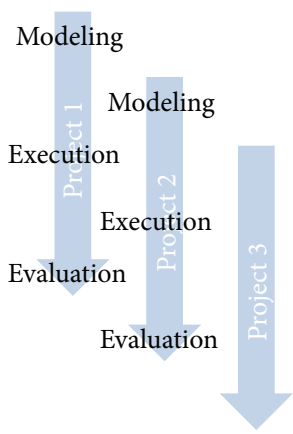

(a) Conventional method

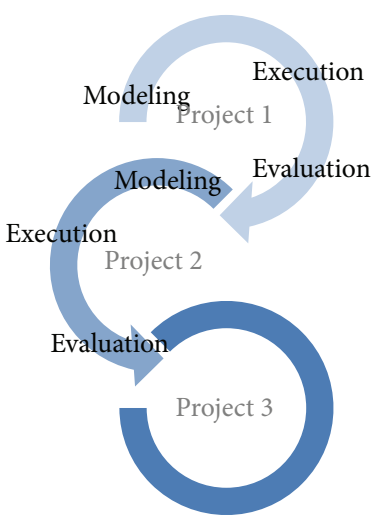

(b) New method using proposed default value

FIgURE 1: Image of simulation flow.

image of the simulation process using a conventional method (Figure 1(a)), in contrast to the simulation process displayed in Figure 1(b), in which the default values are used that were proposed from previous studies.

Although all building properties are individually inputted using a conventional method (Figure 1(a)), the simulation inputs are transferred from the previous studies using proposed default values in the proposed simulation flow (Figure 1(b)).

In this paper, a more convincing argument is presented to show the significance of the new method. Case studies are performed to optimize window properties under various conditions for the building shape, climate, and building operation modes, such as lighting control and natural ventilation. First, the variation in the optimal window properties under different conditions is investigated. Then, the relationship between the optimal properties and each of the conditions is determined. These relationships are used to develop a strategy for searching for similarities between a new project and previous projects to determine appropriate "default values" for the new project.

This study focuses on window-to-wall ratio (WWR) for two reasons. The first reason is the significance of the impact on the simulation results. The sketches of the building shape and location are discussed at the beginning of building design. Building performance simulations are extremely important because the two factors are critical to the building performance. The default value of WWR is required. Another reason is the feasibility of the proposed method. The window data are easily output from the BIM data, such as the industry foundation classes (IFC) data model [25].

\section{Case Study}

3.1. Calculation Scheme. First, various optimal solutions under different conditions are determined. We consider a window design problem that is often used in case studies for optimization research [26]. A three-story office building model is used in this case study. Several properties of this building model can be set parametrically, so that the influence

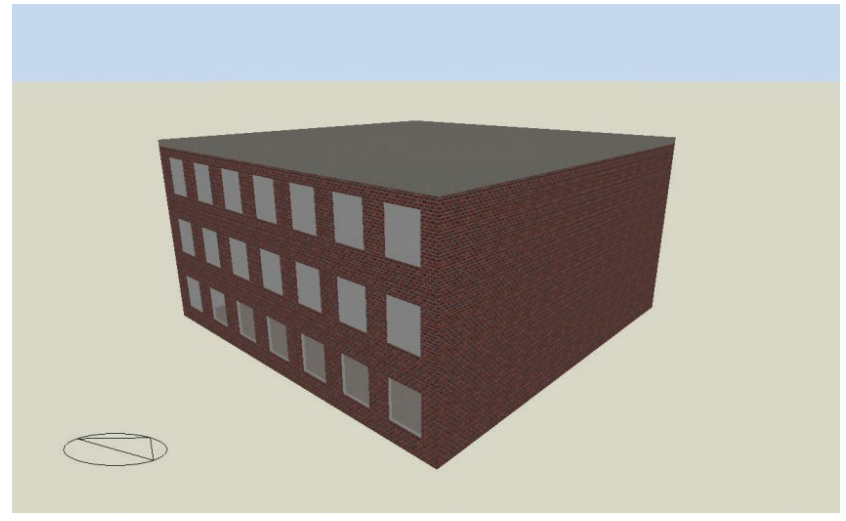

FIGURE 2: Building object.

of default values can be properly investigated. One of these properties is the floor area of one floor, which can be set to 400 or $1600 \mathrm{~m}^{2}$. In this study, only the second floor is considered to determine the building output. The floor height is $3.5 \mathrm{~m}$, including the plenum space.

Figure 2 shows the building object with a floor plan of $400 \mathrm{~m}^{2}$. The building object with an area of $400 \mathrm{~m}^{2}$ is regarded as a small-scale building with a small space depth from the window, whereas the building object with an area of $1600 \mathrm{~m}^{2}$ is regarded as a large-scale building with a large space depth. The design variable for the optimization is the window-to-wall ratio (WWR), which strongly affects the energy use of a building. The glazing is generated for a window height of $2.0 \mathrm{~m}$, but the window height can be adjusted to achieve the required WWR. The objective function is the annual $\mathrm{CO}_{2}$ emission.

Case studies are conducted based on energy simulations for various conditions, building sizes, orientations, building operation modes, such as lighting control and natural ventilation, and weather data. The weather data for ASHRAE/TMY3 in Boston, MA, USA, are chosen to represent a subarctic climate, and the weather data for ASHRAE/TMY3 in Miami, USA, are chosen to represent a subtropical climate. 


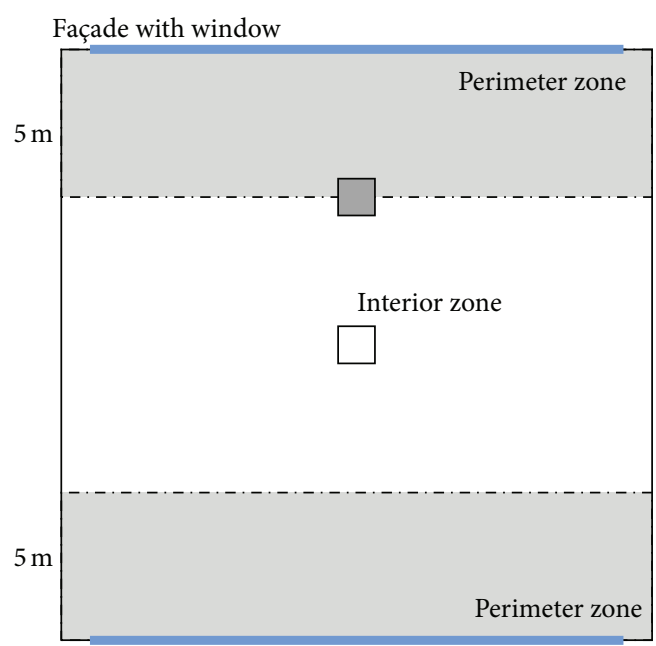

Sensor for perimeter zone

Sensor for interior zone

Figure 3: Sensor locations.

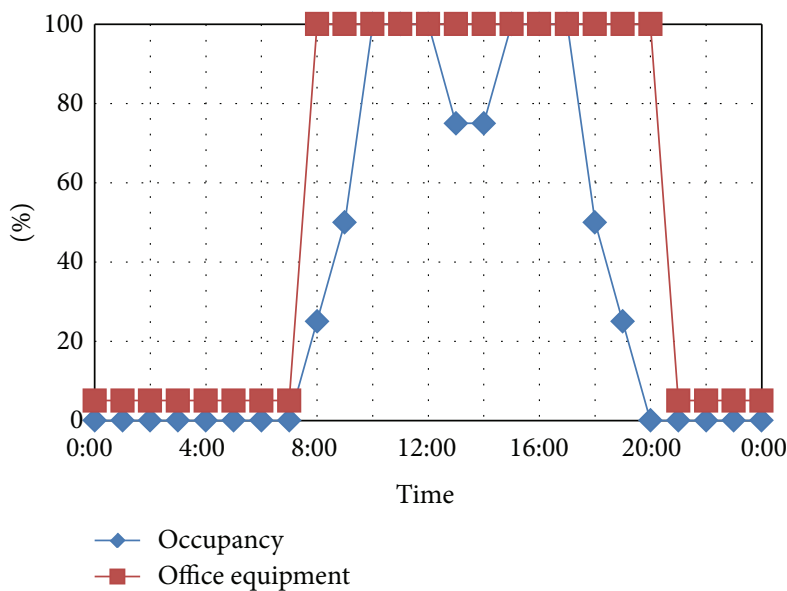

FIGURE 4: Schedule for internal heat load.

Lighting control depending on daylight use is simulated for the building operation. The office area is separated into two zones: a perimeter zone and an interior zone. The perimeter zone is the area that falls within a $5.0 \mathrm{~m}$ distance from a wall with windows. Each zone contains an illuminance sensor. This sensor is located at the center of the office in the interior zone. In the perimeter zone, the sensor is located at the boundary between the two zones. The sensor locations are shown in Figure 3.

Natural ventilation that depends on the external air temperature is simulated. The windows open when the interior air temperature is higher than both the external air temperature and the set point temperature. The set point temperature is $24^{\circ} \mathrm{C}$. The window openings are modulated by the temperature difference between the interior and the exterior. The maximum opening area is $20 \%$ of the window
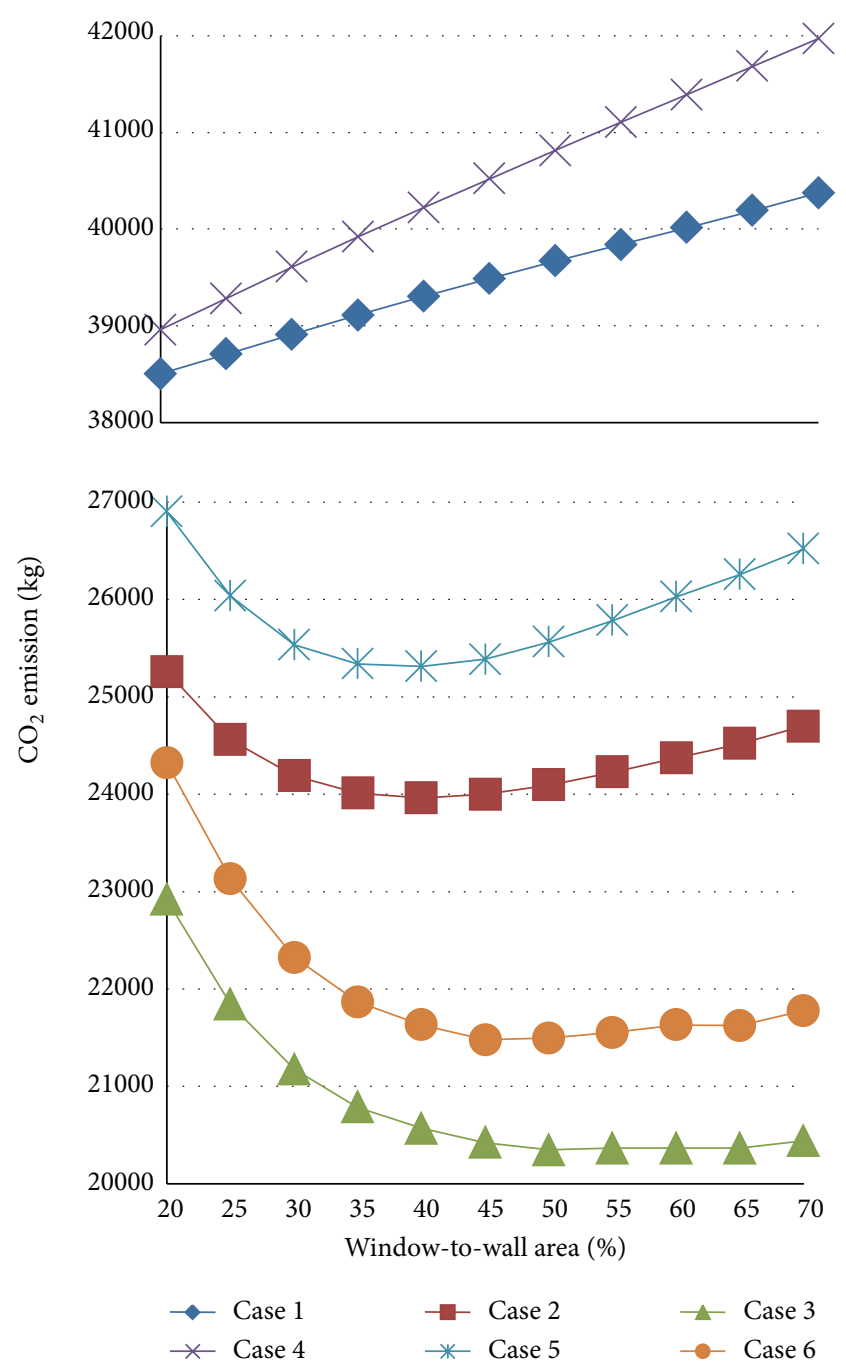

FIGURE 5: Results for cases 1-6.

area. This opening area is multiplied by a factor from 0 to 1 . When the temperature difference between the interior and the exterior is less than $4^{\circ} \mathrm{C}$, this factor is 1 . The factor decreases linearly as the temperature difference increases and becomes 0 for a temperature difference of $8^{\circ} \mathrm{C}$. The ventilation is cross ventilation. The ventilation rate through each opening is calculated based on the pressure difference using wind pressure effect.

The variable conditions for the case studies are shown in Table 1. The remaining conditions are the same for each case, as shown in Table 2. The activity schedules are shown in Figure 4. Design Builder [27] integrating Energy Plus [28] simulation engine were used for the simulations. Only the energy consumption of the second floor is considered in these case studies.

3.2. Calculation Results (Boston). Figure 5 shows the calculation results for cases 1-6, using the weather data from Boston for a floor area of $400 \mathrm{~m}^{2}$. In cases 1 and 4, neither the lighting control nor the natural ventilation control are simulated. 
TABLE 1: Variable conditions for the case studies.

\begin{tabular}{|c|c|c|c|c|}
\hline Case & Operation & Window orientation & Area of each floor $\left[\mathrm{m}^{2}\right]$ & Weather data \\
\hline 1 & None & & \multirow{6}{*}{400} & \multirow{12}{*}{ Boston } \\
\hline 2 & Lighting control & North and South & & \\
\hline 3 & Lighting control, natural ventilation & & & \\
\hline 4 & None & & & \\
\hline 5 & Lighting control & East and West & & \\
\hline 6 & Lighting control, natural ventilation & & & \\
\hline 7 & None & & \multirow{6}{*}{1600} & \\
\hline 8 & Lighting control & North and South & & \\
\hline 9 & Lighting control, natural ventilation & & & \\
\hline 10 & None & \multirow{3}{*}{ East and West } & & \\
\hline 11 & Lighting control & & & \\
\hline 12 & Lighting control, natural ventilation & & & \\
\hline 13 & None & \multirow{4}{*}{ North and South } & \multirow{6}{*}{400} & \multirow{12}{*}{ Miami } \\
\hline 14 & Lighting control & & & \\
\hline 15 & Lighting control, natural ventilation & & & \\
\hline 16 & None & & & \\
\hline 17 & Lighting control & \multirow[t]{3}{*}{ East and West } & & \\
\hline 18 & Lighting control, natural ventilation & & & \\
\hline 19 & None & & \multirow{6}{*}{1600} & \\
\hline 20 & Lighting control & \multirow[t]{3}{*}{ North and South } & & \\
\hline 21 & Lighting control, natural ventilation & & & \\
\hline 22 & None & & & \\
\hline 23 & Lighting control & \multirow[t]{2}{*}{ East and West } & & \\
\hline 24 & Lighting control, natural ventilation & & & \\
\hline
\end{tabular}

TABLE 2: Simulation conditions.

\begin{tabular}{|c|c|}
\hline$U$ value & $\begin{array}{l}\text { Outer wall: } 0.25 \mathrm{~W} / \mathrm{m}^{2} \mathrm{~K} \text { (concrete block and brickwork) } \\
\text { Ground floor: } 0.15 \mathrm{~W} / \mathrm{m}^{2} \mathrm{~K} \text {, roof: } 0.15 \mathrm{~W} / \mathrm{m}^{2} \mathrm{~K} \\
\text { Window: } 1.96 \mathrm{~W} / \mathrm{m}^{2} \mathrm{~K} \text { (double glazing) }\end{array}$ \\
\hline Window & $\begin{array}{l}\text { Double glazing, } U \text { value: } 1.96 \mathrm{~W} / \mathrm{m}^{2} \mathrm{~K} \text {, total solar transmission (SHGC): } 0.70 \text {, direct solar transmission: } 0.62 \text {, } \\
\text { and light transmission: } 0.74\end{array}$ \\
\hline Window shading & $\begin{array}{l}\text { Blind with high reflectivity slats } \\
\text { Solar setpoint for cases } 1,5,9,13: 120 \mathrm{~W} / \mathrm{m}^{2} \\
\text { Maximum allowable glare index for the other cases: } 22.0\end{array}$ \\
\hline Internal heat & Human: 0.1 person $/ \mathrm{m}^{2}, 123 \mathrm{~W} /$ person, office equipment: $11.8 \mathrm{~W} / \mathrm{m}^{2}$ \\
\hline Lighting & $\begin{array}{l}3.3 \mathrm{~W} / \mathrm{m}^{2}-100 \mathrm{lux} \\
\text { Target illuminance: } 400 \mathrm{~lx}\end{array}$ \\
\hline Mechanical ventilation & $10 \mathrm{~L} / \mathrm{s}$-person \\
\hline Heating & $\begin{array}{l}\text { Natural gas (carbon emission factor: } 0.195 \mathrm{~kg} \mathrm{CO} / \mathrm{kWh} \text { ) } \\
\text { Heating system CoP: } 0.830 \\
\text { Schedule: 5:00-19:00 in weekday: on, all other periods: on by set-back temp. } \\
\text { Setpoint temperature: } 22^{\circ} \mathrm{C} \text {, set-back temperature: } 12^{\circ} \mathrm{C}\end{array}$ \\
\hline Cooling & $\begin{array}{l}\text { Electricity from grid (carbon emission factor: } 0.685 \mathrm{~kg} \mathrm{CO} / \mathrm{kWh}) \\
\text { Cooling system CoP: } 1.670 \\
\text { Schedule: 5:00-19:00 in weekday: on, all other periods: off } \\
\text { Setpoint temperature: } 26^{\circ} \mathrm{C}\end{array}$ \\
\hline
\end{tabular}

In these two cases, the larger the WWR, the higher the $\mathrm{CO}_{2}$ emissions. The cooling load increases with the window area due to the increase in solar gain and heat transmittance through the window.
In cases 2 and 5, daylight-dependent lighting controls are simulated. In these two cases, the $\mathrm{CO}_{2}$ emissions are clearly reduced by using lighting control in comparison to cases 1 and 4 , in which lighting control is not used. Increasing 


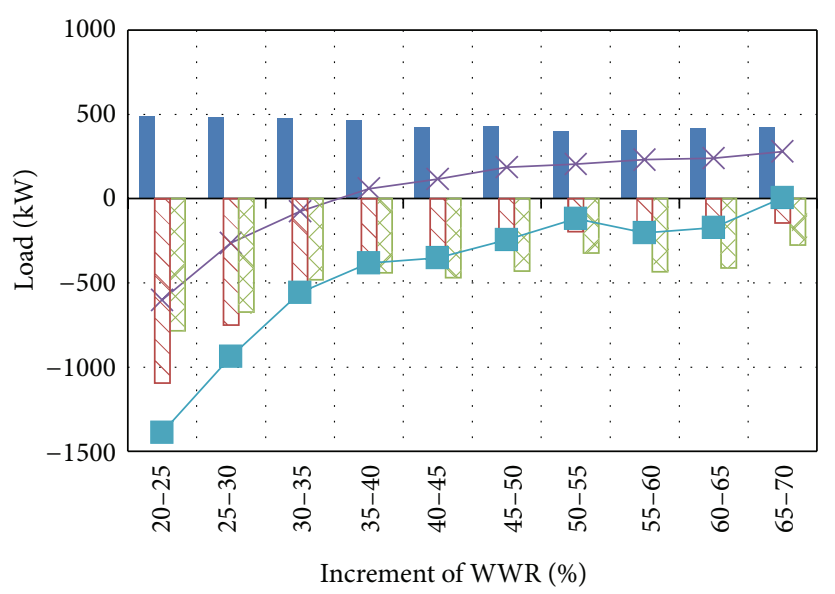

$$
\begin{aligned}
& \text { (a) Increment in cooling load in case } 1 \\
& \square \text { (b) Reduction in lighting load in case } 2 \\
& \square \times \text { (c) Increment in cooling effect by natural ventilation in case } 3 \\
& \star \text { (a) }+ \text { (b) } \\
& - \text { (a) }+ \text { (b) }+ \text { (c) }
\end{aligned}
$$

Figure 6: Influence of window area.

the window area increases the potential for daylight use. In both cases, this effect is clearly shown for a WWR of approximately $40 \%$. However, this daylight effect saturates when the WWR exceeds 50\%. Moreover, the $\mathrm{CO}_{2}$ emissions increase with the window area. The results seem to be comparable to other evaluation results in references [29] and the ANSI/ASHRAE/IESNA1 Standard 90.1-2010, which attained a maximum WWR of $40 \%$. Thus, increasing the window area beyond $50 \%$ of the wall area is not effective for reducing $\mathrm{CO}_{2}$ emissions.

In cases 3 and 6 , natural ventilation and lighting control are simulated. In these two cases, the effect of cooling by natural ventilation and lighting control can be clearly observed when the WWR reaches 50\%. Beyond this value, the window areas have a small influence on $\mathrm{CO}_{2}$ emissions. Although the $\mathrm{CO}_{2}$ emission rates for cases 4-6, in which the windows face east and west, tend to be larger than those for cases $1-3$, in which the window orientations are north and south, similar trends of increasing $\mathrm{CO}_{2}$ emissions are obtained for larger window areas.

Figure 6 shows the influence of the window area on the cooling load for case 1 , the lighting load reduction achieved with lighting control for case 2, and the cooling effect of natural ventilation in case 3 (see (a), (b), and (c) in Figure 6, resp.). The cooling load in case 1 increases monotonically with the window area. However, the lighting load reduction in case 2 decreases as the window area increases. For the cases in which only lighting control is activated, cases 2 and 5 , the lighting load reduction achieved by lighting control is larger than the increase in the cooling load obtained by increasing the window area up to a certain WWR. An inflection point is then reached at which the lighting load reduction becomes equal to the HVAC load increment (see (a) + (b) in Figure 6). The inflection point occurs at a WWR of $40 \%$ in this case study. Thus, a single optimal WWR can be determined. The optimal WWR is approximately $40 \%$ in cases 2 and 5. As shown in Figure 6, the cooling effect of natural ventilation increases almost monotonically with the window area. For the cases in which both lighting control and natural ventilation are simulated, cases 3 and 6 , the $\mathrm{CO}_{2}$ emission decreases until the glazing percentage reaches approximately $50 \%$, as found for cases 2 and 5 . The influence of the glazing percentage on the $\mathrm{CO}_{2}$ emissions becomes very low because lighting control has a very small effect, whereas the constantly increasing cooling effect of natural ventilation is nearly equal to the increase in the cooling load obtained by increasing the window area (see $(a)+(b)+(c)$ in Figure 6).

Figure 7 shows the results for cases $7-12$, which have floor areas of $1200 \mathrm{~m}^{2}$, and the space depth is large. In cases 7 and 10, neither lighting control nor natural ventilation control are simulated. In these two cases, the larger the WWR, the higher the $\mathrm{CO}_{2}$ emission, as was found for cases 1 and 4 . However, as the window area increases, the $\mathrm{CO}_{2}$ emission monotonically decreases for all of the other cases. Thus, daylight use achieved by increasing the window area is always expected to reduce $\mathrm{CO}_{2}$ emissions, even though the influence gradually decreases. Thus, the design with the highest WWR is the best solution for cases with a relatively large floor area and large space depth.

3.3. Calculation Results (Miami). Figure 8 shows the results for cases 13-18, based on the weather data from Miami for a floor area of $400 \mathrm{~m}^{2}$. Compared to Figure 5, the same trends are observed for the influence of the window area on the $\mathrm{CO}_{2}$ emissions. However, the inflection points of the $\mathrm{CO}_{2}$ emission curve are more obvious than those observed in Figure 5. Although it is difficult to find an optimal WWR in cases 3 and 6 , a window area of $40 \%$ can be used as the optimal percentage in cases 15 and 18. 


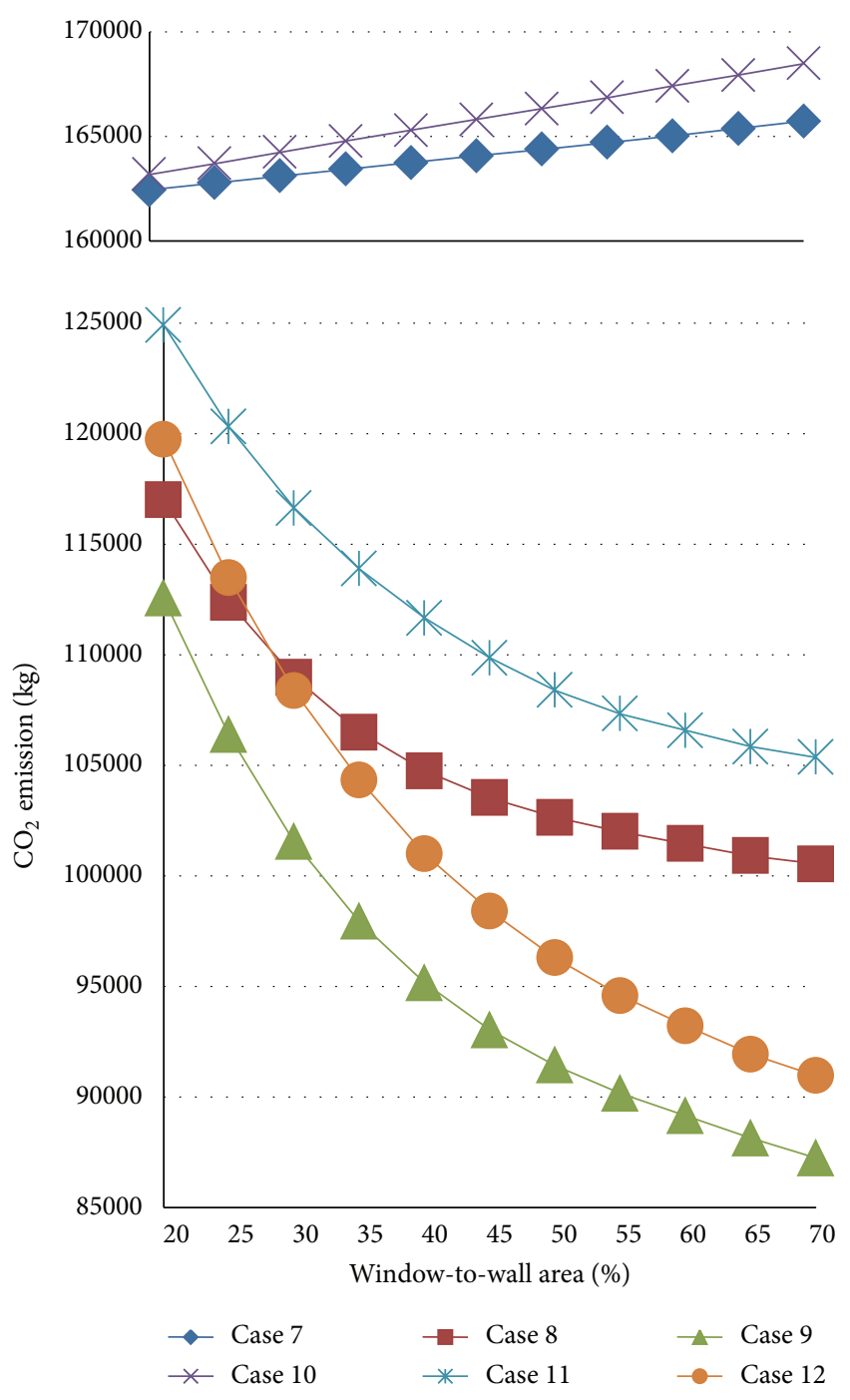

FIgURE 7: Results for cases 7-12.

Figure 9 shows the influence of the window area on the cooling load for case 13, the lighting load reduction for case 14 , and the cooling effect due to natural ventilation in case 15 (see (a), (b), and (c) in Figure 9, resp.). The trends shown in Figures 9 and 6 differ in that the increase in the cooling load is relatively larger than those for the lighting load reduction and the cooling effect by natural ventilation. Thus, when the WWR reaches an inflection point, the lighting load reduction becomes equal to the HVAC load increment (see (a) + (b) in Figure 9). Even for natural ventilation operation, the increment in the cooling load becomes larger than the sum of the lighting load reduction and the cooling effect as the window area increases. Thus, an inflection point can be observed even for the case with natural ventilation (see case 15 in Figure 8 and (a) + (b) + (c) in Figure 9).

Figure 10 shows the results for cases 19-24, which have floor areas of $1200 \mathrm{~m}^{2}$. In comparison to Figure 5, the same trends are observed for the influence of the window area on the $\mathrm{CO}_{2}$ emissions. Thus, the weather data do not exert a significant effect on the optimal window area for cases with

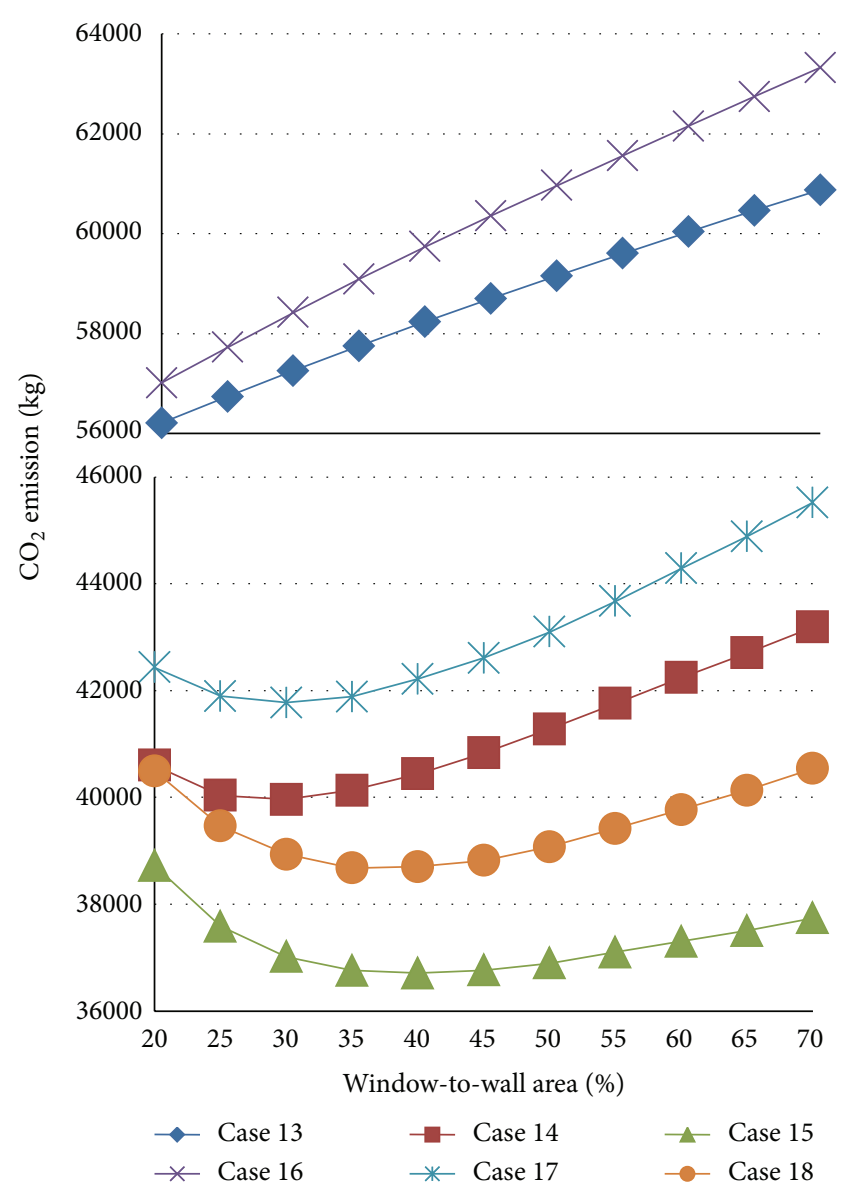

Figure 8: Results for cases 13-18.

a relatively large floor area and a large space depth from window. A reduction in $\mathrm{CO}_{2}$ emissions is expected because the increased window area contributes to a lighting load reduction and the possibility of using natural ventilation in all of the cases considered.

\section{Discussion}

The ideal "default values" referenced in the "Introduction" are discussed in this section. When a building shape sketch is discussed at the early stage of building design, an energy simulation must be implemented to estimate the energy performance of the building. In energy simulations, the window properties, especially the WWR, exert a strong effect on the output. Thus, accurate inputs are needed to obtain an optimal building shape that maximizes the energy performance of the building. However, the window properties are generally not considered at this stage because the building shape sketch is usually considered at the first stage of the building design. Thus, tentative values should be assigned to the window properties to implement the energy simulation. However, these tentative values will be changed at a later stage of building design, when the window properties are treated as design variables. Thus, one must choose a tentative value that minimizes the variation in the calculation results when the value is changed at a later stage in the building design. 

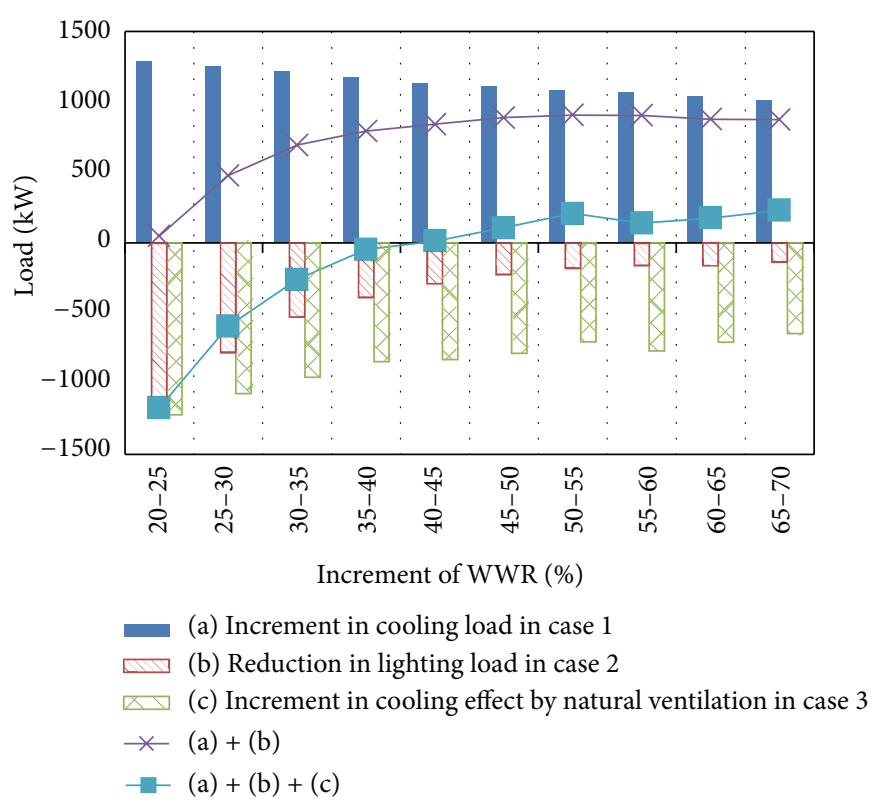

FIGURE 9: Influence of window area.

4.1. Evaluation of Default Value Using Average Value of Error. We illustrate this concept using the case study presented in Section 3. Figure 11 shows the average value of the error when different WWRs are used as tentative values. The average values of the error are calculated using the following equation:

$$
E(i)=\sum_{j} \frac{Q_{i, j}-Q_{\min , j}}{Q_{\min , j}} \times \frac{100}{n},
$$

$E(i)$ is average value of the error [\%], $Q_{i, j}$ is $\mathrm{CO}_{2}$ emission for case $j$ when the tentative WWR is $i \%[\mathrm{~kg}], Q_{\min , j}$ is minimum $\mathrm{CO}_{2}$ emission for case $j[\mathrm{~kg}]$, and $n$ is total number of cases used to calculate the average value.

The error $Q_{i, j}-Q_{\min , j}$ is the amount of change that results from the change in the default value at a subsequent stage in the building design. The amount of change is divided by the minimum $\mathrm{CO}_{2}$ emission $Q_{\min , j}$ as the calculation results using the optimal WWR to express the value as a percentage. The percentage is assumed to be the error range in the simulation results in the initial stages of building design. Minimizing the value of this change maintains the accuracy of the simulation results in the initial stages of building design. In this equation, each value is assumed to have an equal probability of being selected as the default value and the default value is assumed to be optimized to reduce the $\mathrm{CO}_{2}$ emission at a subsequent stage in the building design.

The Boston data are used in the calculations for cases $1-12$, and the Miami data are used in the calculations for cases 13-24. For the cases in which the Boston data are used, the average value of the error is minimized for a WWR of approximately $65 \%$. Thus, a relatively large window area can be used as the ideal default value in a subarctic climate area such as Boston. However, for the Miami cases, the average value of the error is minimized for a certain WWR, such as $40 \%$. Thus, expanding the window area is not necessarily a good strategy for reducing $\mathrm{CO}_{2}$ emissions by daylight use and natural ventilation. A modest WWR should be used as the ideal default value for a subtropical climate area such as Miami.

\subsection{Grouping of Cases to Increase Adequacy in Default Value.} Figure 12 shows the WWRs that produce the minimum average value of the error, grouped by cases with a common building feature. Figure 12(a) shows the results for the cases with a floor area of $400 \mathrm{~m}^{2}$, cases 1-6 and cases 13-18. An optimum WWR of $30 \%$ should be used as the default value for this condition. Figure 12(b) shows the results for cases with a floor area of $1600 \mathrm{~m}^{2}$, cases 7-14 and cases 19-24. In this scenario, an optimum WWR of $70 \%$ should be used as the default value, corresponding to twice the value found for a floor area of $400 \mathrm{~m}^{2}$. This result implies that the default values should be selected based on the space depth related to the floor area. If the building scale is large and the space depth is large, as in case (b), a relatively large ideal default value should be used. The effects of daylight use and natural ventilation can be expected for larger window areas. However, if the building scale is small and the space depth is small, as in case (a), a modest WWR should be used as the ideal default value.

Figures 12(c) and 12(d) show the results for cases in which the window orientations are north/south and east/west, respectively. In both cases, modest WWRs, near 50\%, result in the minimum average value of error. Thus, the window orientation has little effect on the optimal default value.

Figures $12(\mathrm{e}), 12(\mathrm{f})$, and $12(\mathrm{~g})$ show the results for cases with different operation modes of lighting control and natural ventilation. If neither operation is employed, as in case (e), the window area should be minimized because increasing the window area directly increases the HVAC load. However, when lighting control is used, increasing the window area is 


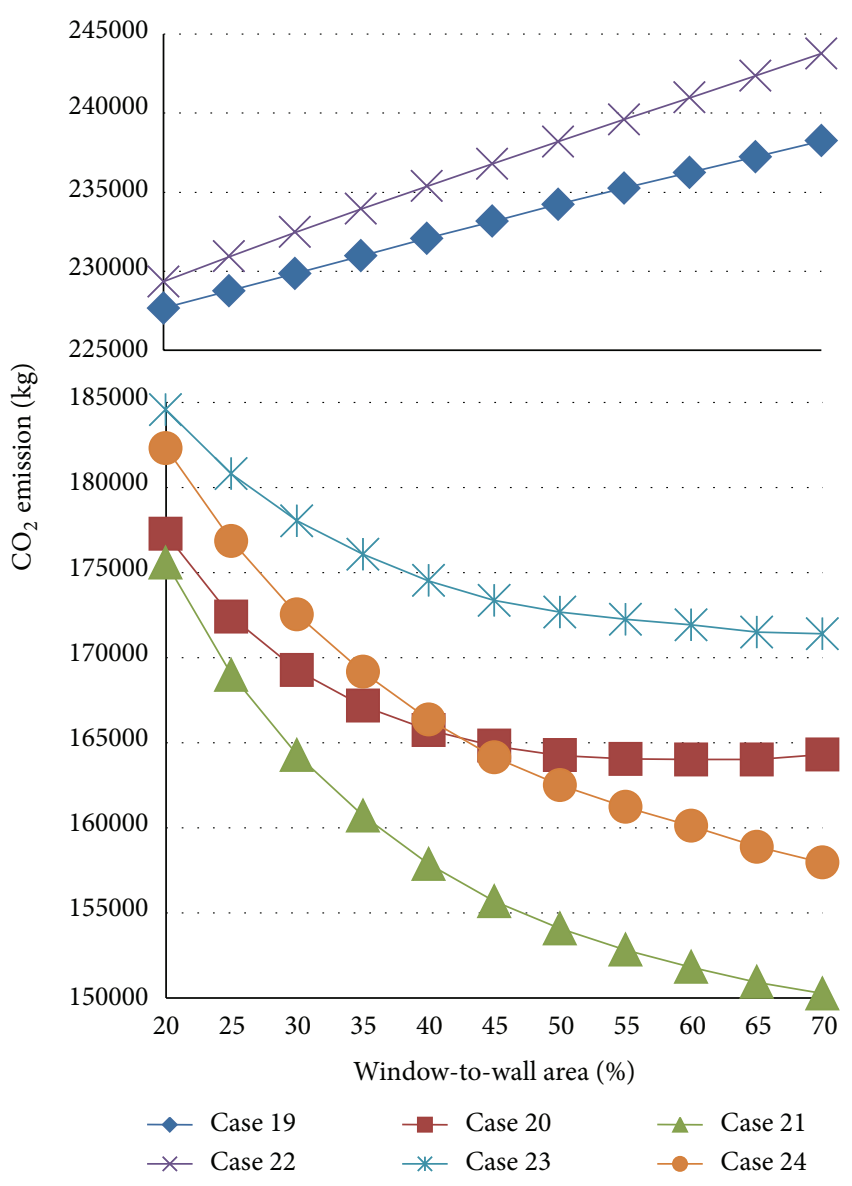

FIgURE 10: Results for cases 19-24.

an appropriate strategy for reducing $\mathrm{CO}_{2}$ emissions. Then, a modest WWR can be used as the default value. When both lighting control and natural ventilation are utilized, an increased window area tends to reduce $\mathrm{CO}_{2}$ emissions. In this case, a large window area should be used as the default value. The installation of a ventilation tower could also be considered as a default input for an energy simulation because the natural ventilation effect does not saturate, even at the highest WWR. These results imply that the presence or absence of these operation modes must be included at the early stage of building design to increase the precision of the simulation at this stage.

\section{Conclusions}

To minimize the magnitude of the change in the default values, the default values should be chosen in accordance with the building design conditions, such as the building scale, location, and operation mode, including lighting control and natural ventilation. In this study, we first confirm that the ideal default values depend on the building design conditions. When a building scale and space depth are relatively small, each case has a different optimal WWR. The optimal window sizes vary depending on the climate condition and the building operation mode. However, for

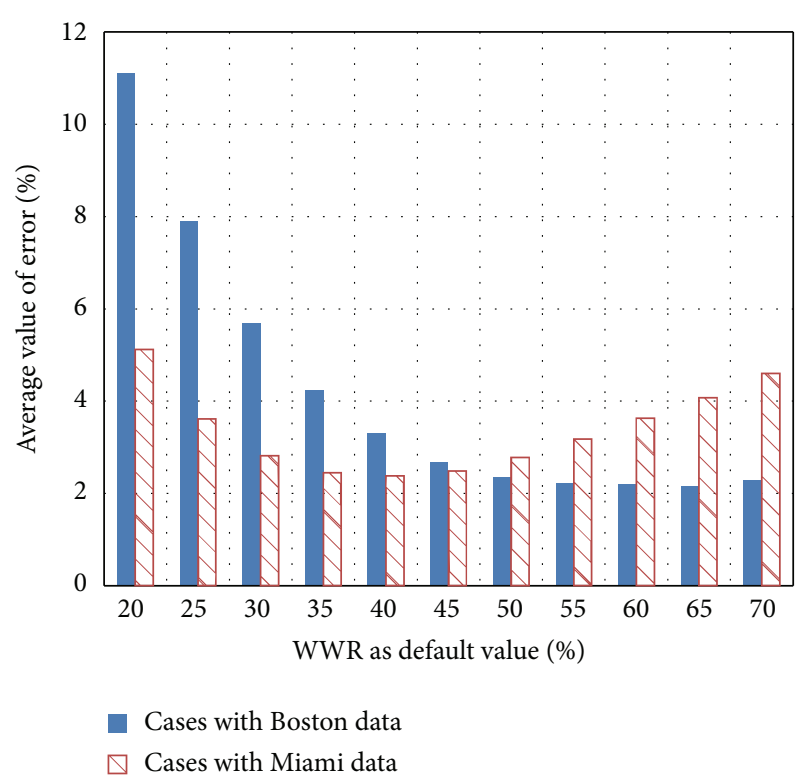

Figure 11: Average value of the error.

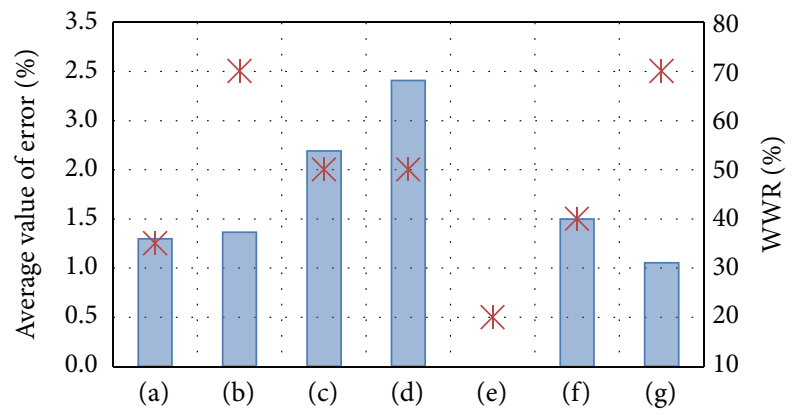
(a) Floor area of $400 \mathrm{~m}^{2}$
(b) Floor area of $1600 \mathrm{~m}^{2}$
(c) Window orientations are north and south
(d) Window orientations are east and west
(e) No operation strategy used
(f) Lighting control implemented
(g) Lighting control and natural ventilation implemented
Average value of error
X WWR

FIGURE 12: WWRs that produce a minimum average value of the error.

buildings with relatively large scales with large space depths, an increase in the window area is an appropriate strategy for any climate condition.

Then, we investigate the influence of each condition on the variation in the ideal default values for the WWR. These effects can be used to determine the types of building conditions that should be considered when selecting the ideal default values for a new building design project. In the case studies considered, the building scale and the space depth are found to have a large impact on the ideal default value of the WWR, whereas the window orientation has little impact. In addition, the presence or absence of lighting control and natural ventilation has a significant influence on the ideal 
default value. Thus, the operation mode must be chosen at the early stage of the building design because these elements are critical in determining the optimal window area.

This study focuses on the WWR because the value has a significant impact on the energy simulation results. The concept of an ideal default value can presumably be adapted to any input required for building performance simulations. In future studies, the author plans to apply the idea to other inputs, such as the inputs required for template files of standardized building properties [15].

\section{Conflict of Interests}

The author declares that there is no conflict of interests regarding the publication of this paper.

\section{Acknowledgment}

This work was supported by JSPS KAKENHI Grant no. 25709051.

\section{References}

[1] A. T. Nguyen, S. Reiter, and P. Rigo, "A review on simulationbased optimization methods applied to building performance analysis," Applied Energy, vol. 113, pp. 1043-1058, 2014.

[2] V. Granadeiro, J. P. Duarte, J. R. Correia, and V. M. S. Leal, "Building envelope shape design in early stages of the design process: integrating architectural design systems and energy simulation," Automation in Construction, vol. 32, pp. 196-209, 2013.

[3] S. Attia, E. Gratia, A. de Herde, and J. L. M. Hensen, "Simulation-based decision support tool for early stages of zeroenergy building design," Energy and Buildings, vol. 49, pp. 2-15, 2012.

[4] C. Eastman, P. Teicholz, R. Sacks, and K. Liston, BIM Handbook: A Guide to Building Information Modeling for Owners, Managers, Designers, Engineers and Contractors, Wiley, 2008.

[5] R. Volk, J. Stengel, and F. Schultmann, "Building Information Modeling (BIM) for existing buildings-literature review and future needs," Automation in Construction, vol. 38, pp. 109-127, 2014.

[6] Y. Diao, S. Kato, and K. Hiyama, "Development of an optimal design aid system based on building information modeling," Building Simulation, vol. 4, no. 4, pp. 315-320, 2011.

[7] K. Hiyama, S. Kato, M. Kubota, and J. Zhang, "A new method for reusing building information models of past projects to optimize the default configuration for performance simulations," Energy and Buildings, vol. 73, pp. 83-91, 2014.

[8] V. Granadeiro, J. R. Correia, V. M. S. Leal, and J. P. Duarte, "Envelope-related energy demand: a design indicator of energy performance for residential buildings in early design stages," Energy and Buildings, vol. 61, pp. 215-223, 2013.

[9] J. Parasonis, A. Keizikas, and D. Kalibatiene, "The relationship between the shape of a building and its energy performance," Architectural Engineering and Design Management, vol. 8, no. 4, pp. 246-256, 2012.

[10] G. K. Oral and Z. Yilmaz, "Building form for cold climatic zones related to building envelope from heating energy conservation point of view," Energy and Buildings, vol. 35, no. 4, pp. 383-388, 2003.

[11] P. Depecker, C. Menezo, J. Virgone, and S. Lepers, "Design of buildings shape and energetic consumption," Building and Environment, vol. 36, no. 5, pp. 627-635, 2001.

[12] A. Skowronski, "Optimum building shape in view of energy saving," in Universal Access in Human-Computer Interaction. Design Methods, Tools, and Interaction Techniques for eInclusion, vol. 8009 of Lecture Notes in Computer Science, pp. 339-347, Springer, Berlin, Germany, 2013.

[13] F. Talbourdet, P. Michel, F. Andrieux, J.-R. Millet, M. E. Mankibi, and B. Vinot, "A knowledge-aid approach for designing high-performance buildings," Building Simulation, vol. 6, no. 4, pp. 337-350, 2013.

[14] I. Axaopoulos, P. Axaopoulos, and J. Gelegenis, "Optimum insulation thickness for external walls on different orientations considering the speed and direction of the wind," Applied Energy, vol. 117, pp. 167-175, 2014.

[15] C. Cerezo, T. Dogan, and C. Reinhart, “Towards standardized building properties template files for early design energy model generation," in Proceedings of the ASHRAE/IBPSA-USA Building Simulation Conference, pp. 25-32, Atlanta, Ga, USA, 2014.

[16] S. G. Attia and A. De Herde, "Early design simulation tools for net zero energy buildings: a comparison of ten tools," in Proceedings of the 12th Conference of the International Building Performance Simulation Association, pp. 94-101, Sydney, Australia, November 2011.

[17] C. J. Hopfe, G. L. M. Augenbroe, and J. L. M. Hensen, "Multi-criteria decision making under uncertainty in building performance assessment," Building and Environment, vol. 69, pp. 81-90, 2013.

[18] J. Huang, H. Lv, T. Gao, W. Feng, Y. Chen, and T. Zhou, "Thermal properties optimization of envelope in energy-saving renovation of existing public buildings," Energy and Buildings, vol. 75, pp. 504-510, 2014.

[19] S. Liu, J. Liu, Q. Yang et al., "Coupled simulation of natural ventilation and daylighting for a residential community design," Energy and Buildings, vol. 68, pp. 686-695, 2014.

[20] B. Lee, M. Trcka, and J. L. M. Hensen, "Building energy simulation and optimization: a case study of industrial halls with varying process loads and occupancy patterns," Building Simulation, vol. 7, no. 3, pp. 229-236, 2014.

[21] C. van Dronkelaar, D. Cóstola, R. A. Mangkuto, and J. L. M. Hensen, "Heating and cooling energy demand in underground buildings: potential for saving in various climates and functions," Energy and Buildings, vol. 71, pp. 129-136, 2014.

[22] L. Wang and F. Leite, "Knowledge discovery of spatial conflict resolution philosophies in BIM-enabled MEP design coordination using data mining techniques: a proof-of-concept," in Proceedings of the ASCE International Workshop on Computing in Civil Engineering (WCCE '13), pp. 419-426, Los Angeles, Calif, USA, June 2013.

[23] J. O’Donnell, R. See, C. Rose, T. Maile, V. Bazjanac, and P. Haves, "SimModel: A domain data model for whole building energy simulation," in Proceedings of the 12th Conference of International Building Performance Simulation Association Building Simulation (BS '11), pp. 382-389, Sydney, Australia, November 2011.

[24] K. Hiyama, M. Kubota, and S. Kato, "Generation of default configuration for environment simulations: optimal building design support system utilizing reuse of BIM data," Journal of Environmental Engineering, vol. 78, no. 686, pp. 367-374, 2013. 
[25] H. Kim and K. Anderson, "Energy modeling system using building information modeling open standards," Journal of Computing in Civil Engineering, vol. 27, no. 3, pp. 203-211, 2013.

[26] K. Suga, S. Kato, and K. Hiyama, "Structural analysis of Pareto-optimal solution sets for multi-objective optimization: an application to outer window design problems using Multiple Objective Genetic Algorithms," Building and Environment, vol. 45, no. 5, pp. 1144-1152, 2010.

[27] DesignBuilder Software, “Design Builder," http://www.designbuilder.co.uk/.

[28] D. B. Crawley, L. K. Lawrie, F. C. Winkelmann et al., "EnergyPlus: creating a new-generation building energy simulation program," Energy and Buildings, vol. 33, no. 4, pp. 319-331, 2001.

[29] R. Azari, "Integrated energy and environmental life cycle assessment of office building envelopes," Energy and Buildings, vol. 82, pp. 156-162, 2014. 

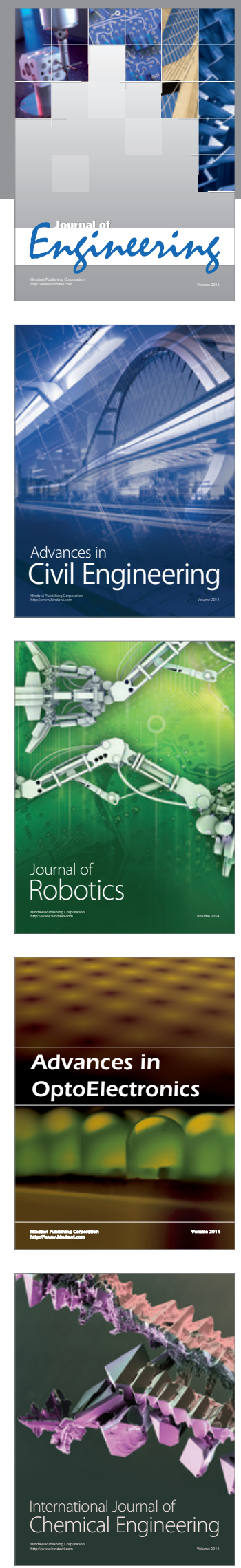

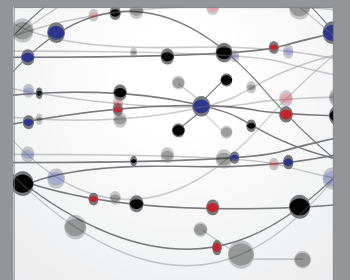

The Scientific World Journal
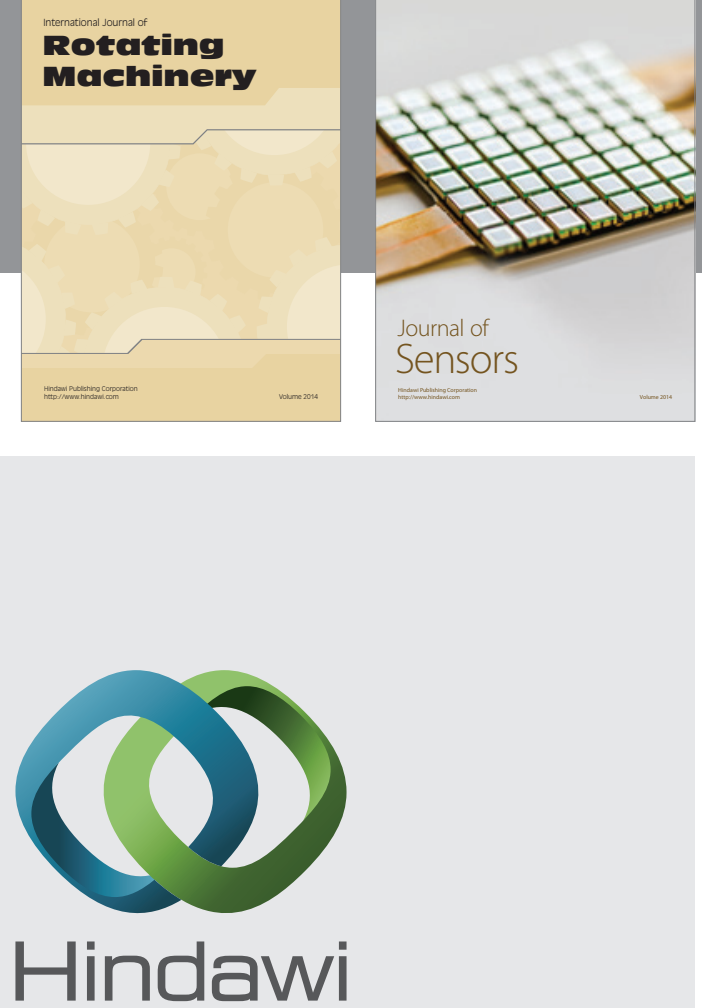

Submit your manuscripts at http://www.hindawi.com
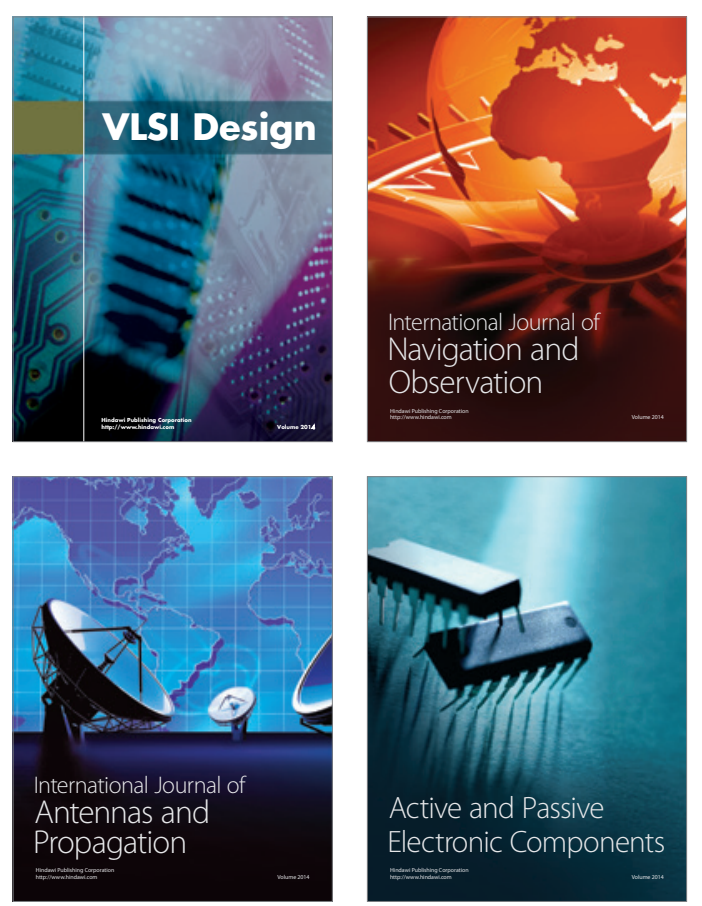
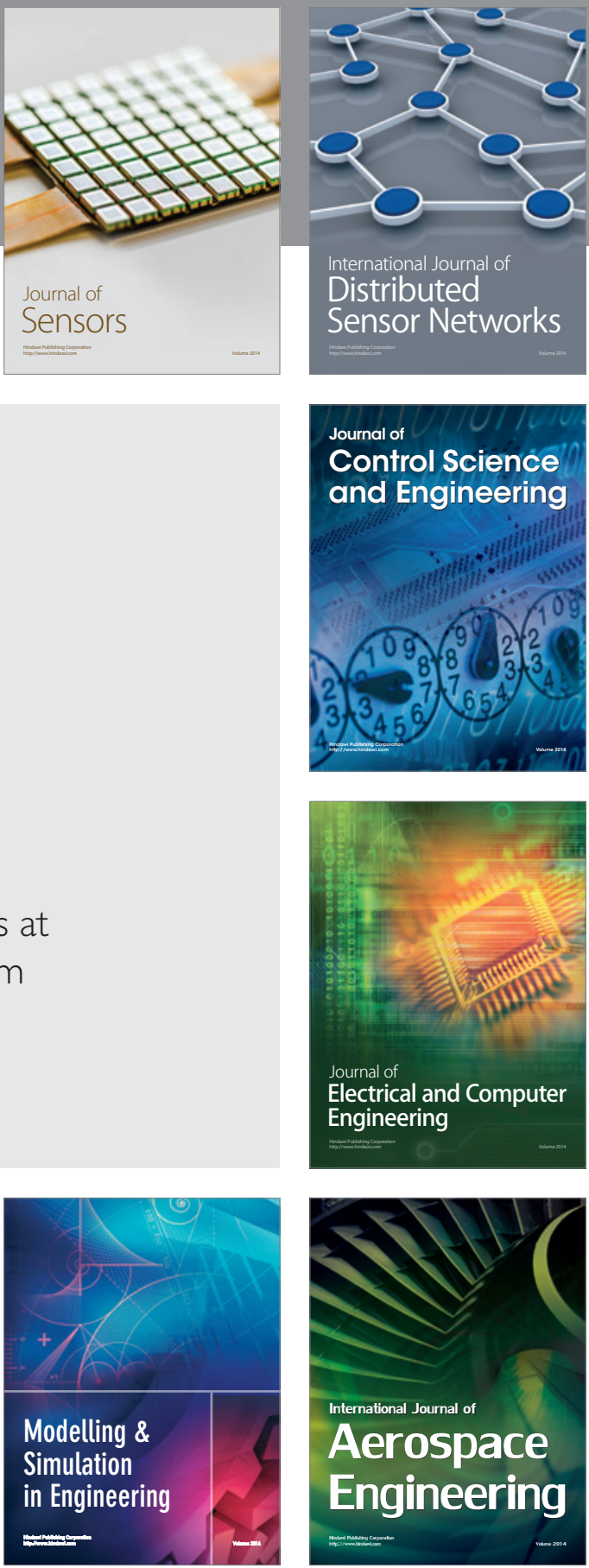

Journal of

Control Science

and Engineering
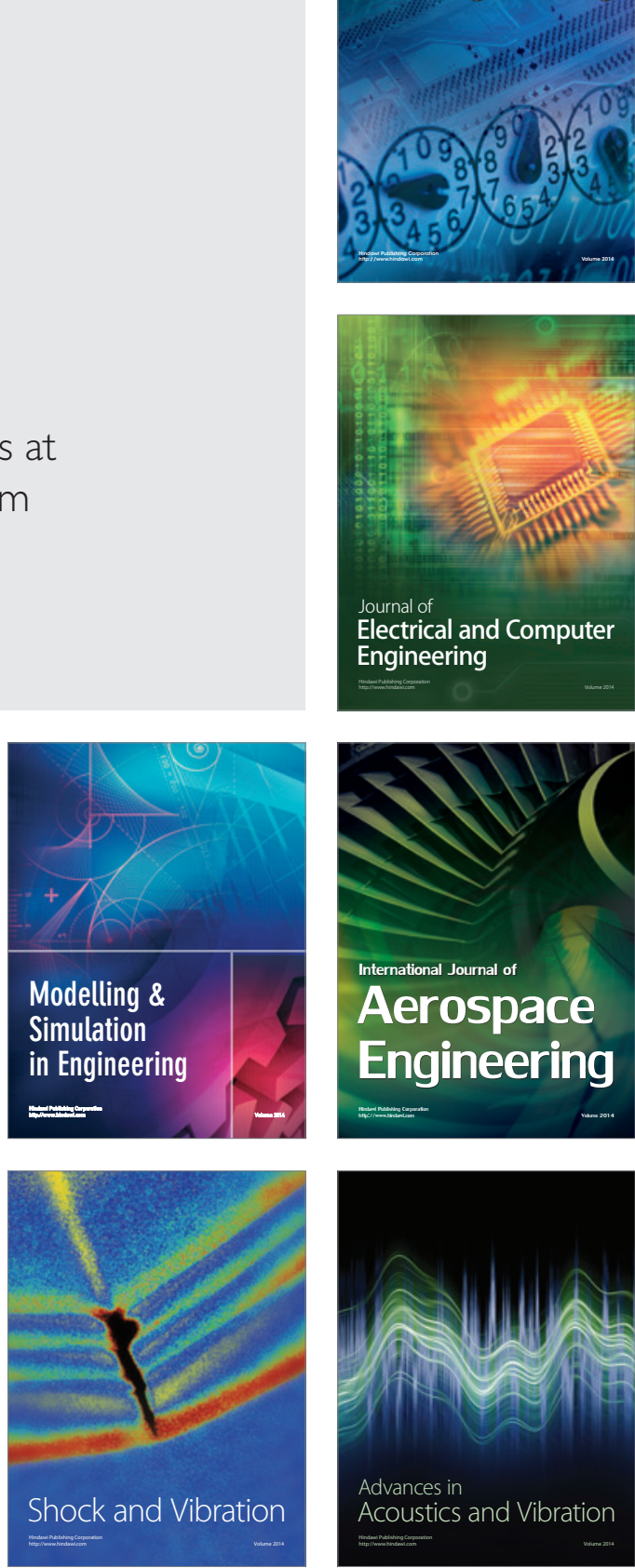